\title{
Towards an epistemological understanding of healthcare informatics: Academic backgrounds of the faculty
}

\author{
Thomas James Virgona * \\ Adelphi University, Garden City, United States
}

\author{
Received: January 4, 2015 \\ Accepted: March 1, 2015 \\ Online Published: March 17, 2015 \\ DOI: $10.5430 /$ jnep.v5n6p9 \\ URL: http://dx.doi.org/10.5430/jnep.v5n6p9
}

\begin{abstract}
Healthcare informatics is a relatively new field to academia and is multi-disciplinary by nature. Although the field of health informatics encompasses several disciplines and subject areas that are familiar and long standing, the field itself is still in a formative state that allows many disciplines to contribute to the field through teaching and curriculum development in a way that may not be possible in more established educational programs. The purpose of this pilot study was to start to define the cross-disciplinary nature of a Healthcare Informatics faculty. Researchers in the field agree that the discipline includes a full spectrum of courses, but the diversity of faculty backgrounds remains vague. In this pilot study, one trend was apparent in the academic backgrounds of the Healthcare Informatics faculty; Computer Science was the most common academic background of the faculty (10 PhD's, 8 Graduate and 6 Undergraduate Degrees). Interestingly, four faculty members earned a PhD in Health Informatics and no faculty member had earned a graduate/undergraduate degree in Healthcare informatics. The faculty members of the ten universities investigated in this pilot study indicated 45 unique Doctoral disciplines. By any measure, that would be considered inter-disciplinary.
\end{abstract}

Key Words: Healthcare informatics, Faculty skills, Cross-discipline curriculum

\section{INTRODUCTION}

Healthcare Informatics is a relatively new field to academia and is multi-disciplinary by nature. ${ }^{[1]}$ Although the field of health informatics encompasses several disciplines and subject areas that are familiar and long standing, the field itself is still in a formative state that allows many disciplines to contribute to the field through teaching and curriculum development in a way that may not be possible in more established educational programs. ${ }^{[2]}$ While academic medical informatics programs are established at few medical institutions in the United States, increasing numbers of schools are considering this field of study and many traditional depart- ments are seeking and attracting individuals with medical informatics skills. ${ }^{[3]}$ There is not a common consensus on what defines those skills. The logical extension and question is; with a new inter-disciplinary field, what are the academic backgrounds of the faculty teaching this new area? Bakken ${ }^{[4]}$ stated that informatics competencies are an essential building block for an evidence-based nursing practice. However, Bakken does not address how those skills should be obtained.

\subsection{Literature review}

Despite the increasing mandate for use of health Information Technology (IT) systems in organizations, we do not have comprehensive knowledge of the backgrounds, train-

*Correspondence: Thomas James Virgona; Email: tvirgona@adelphi.edu; Address: Adelphi University, South Ave, Garden City, United States. 
ing, and skills of those who work within the field. There is an absence of information about those who have clinical/technology backgrounds and work in Healthcare Information Technology (HIT) settings. The importance of this workforce, however, is increasingly acknowledged by leaders in HIT. Dr. David Brailer, Director of the Office of the National Coordinator for HIT (ONCHIT) has stated "We have a huge manpower crisis coming down the road" in the implementation of HIT systems. Drs. Charles Safran and Don Detmer, of the American Medical Informatics Association (AMIA), have called for at least one physician and nurse each at all 6,000 hospitals in the United States to be trained in medical informatics and guide HIT implementation in their local settings. ${ }^{[5]}$

Medical information systems will continue to evolve with or without staff trained specifically in health care informatics. Some of the very talented and innovative people who are now leaders in health care IT come from very different backgrounds, but lack any formal education in medical informatics. One incentive is a financial package that recognizes that health care informatics staff could use their skills in other industries in which pay levels are higher. ${ }^{[6]}$

A 2003 study addressed the specific issue of who is teaching technology to healthcare professions. A nursing model has been used in this discussion, as the current research does not have an adequate healthcare model. The nursing model found that faculty, who were rated at the "novice" or "advanced beginner" in information technology content and use of information technology tools, are teaching information literacy skills. The southeastern central and Pacific regions of the United States projected the greatest need for information technology-prepared nurses. Using Benner's (1984) novice to expert framework, only 2 programs rated their nursing faculty as experts in teaching and using information technology. Most nursing programs rated their faculty at the advanced beginner level. Significantly, $18 \%$ of programs reported their faculty as novices. Twenty-nine percent of nursing programs reported their faculty members were at the competent level. However, $46 \%$ of programs reported either no future plans or no knowledge of any plans to offer information technology education or training in their region. ${ }^{[7]}$

The boundaries of healthcare informatics are not well defined. Are individuals who work in information technology departments of medical centers medical informaticians? Are librarians informaticians? There is no common informatics curriculum, nor any common job that anyone with training in the field could define. ${ }^{[8]}$

Research has found the right mix between research/training and service requirements may be challenging. The goal is to attract faculty who understand informatics as science, not just as means to reach pragmatic ends (e.g., find a job). Possibly joint appointments for faculty from other units or primary appointments only for informaticians may be a future option. ${ }^{[9]}$

One of the benefits of an education in healthcare informatics is the opportunity to interact with professionals from diverse backgrounds, thereby gaining an appreciation for the varied perspectives, vocabularies and values of each domain. This can be a critical factor in arriving at a solution to a problem. One example of divergent vocabularies emerged in a course in which one of the students commented, "I suddenly recognized the challenges inherent in health informatics when I realized that 'HIT' refers to 'health information technology', not 'hemolytic idiopathic thrombocytopenia'". Programs administered across many academic departments bring diverse perspectives together to determine course content, admissions standards, curriculum and degree requirements. ${ }^{[10]}$

As the internet has removed geographic barriers, this issue is not solely a concern in the United States. Although not the focus of this research, the issue appears to be a global question. In Slovakia, the curriculum content and the quality of education varied among providers and programs. In one research study, the total number of faculty members representing Slovakia was about 40, with different qualifications for academic degrees and professional preparation. The opportunities for further career development and training of students after graduation were not clearly defined. Additionally, the criteria for program self-assessment are not academically sufficient. ${ }^{[11]}$

\subsection{Research purpose and questions}

The purpose of this pilot study was to start to define the cross-disciplinary nature of a Healthcare Informatics faculty. Researchers in the field agree that the discipline includes a full spectrum of courses, but the diversity of faculty backgrounds remains vague. Consequently, this study addresses fundamental questions:

- What are the academic backgrounds of Healthcare Informatics faculty?

- Do the disciplines mirror the inter-disciplinary nature if the Healthcare Informatics field itself?

\section{Methodology}

For this study, a content analysis of Healthcare Informatics graduate/doctorate degree professors was conducted, using a representative sample of universities. The design goal was to construct a sample frame corresponding to the population (Universities/Colleges). ${ }^{[12]} \mathrm{A}$ web search was conducted to obtain the academic backgrounds of healthcare informatics professors. 
Content analysis requires two processes: definition of the content characteristics (basic content elements) being examined and application of rules for identifying and recording these characteristics. An objective coding scheme must be applied to the courses. ${ }^{[13]}$ For this pilot study, a Web search was conducted to obtain the following data elements:

- Name of Professor

- Teaching At

- Title

- Doctoral Degree Area

- Doctorate Granted at

- Masters Subject

- Masters Granted at

- Bachelors Subject

- Bachelors Granted at

- Notes

One design issue is how well the sample frame corresponds to the population a researcher wants to describe. Searching for healthcare informatics professors web pages potentially has limitations in identifying all relevant academic backgrounds. ${ }^{[14]}$ Extensive browsing and keyword searching of program web pages was conducted to verify and update faculty details. Healthcare Informatics curriculums may lean towards a more business or medical viewpoint. As such, a limit of thirteen professors per university was set to ensure one university would not skew the results.

Is this a true picture? By using a reprehensive sample, the goal was that the information derived from the sample and the conclusions reflected the same conditions that exist in University settings as a whole. ${ }^{[15]}$ Specifically excluded from the sample was "for-profit universities", defined as colleges that are owned and operated by businesses and are ultimately accountable by law for the returns they produce for shareholders. ${ }^{[16]}$ The sample selected for this pilot study (January 2014) will be universities have a Graduate and/or Doctoral program and meet one of the following criteria:

- Traditional/On the ground

- Public or Private institution

- Large School

Table 1 shows the working definitions used for this study.

\section{Findings}

For this pilot study, 65 faculty members from 10 universities were analyzed. The ten universities selected and the number of faculty included in this pilot study are shown in Table 2.

Table 1. Working definitions of universities

\begin{tabular}{|c|c|}
\hline Term & Definition \\
\hline & Large Universities have more than 15,000 students. $^{[17]}$ \\
\hline Large university & $\begin{array}{l}\text { "Large university" means a university that produces more than } 150,000 \text { student credit hours per } \\
\text { academic year. Although a more detailed criteria, credit hours is not readily available. }{ }^{[18]}\end{array}$ \\
\hline & Small Universities have fewer than 5,000 students. ${ }^{[17]}$ \\
\hline Small university & $\begin{array}{l}\text { "Small university" means a university that produces } 150,000 \text { or fewer student credit hours per } \\
\text { academic year. }{ }^{[18]} \text { Although a more detailed criterion, credit hours are not readily available. }\end{array}$ \\
\hline Private University & $\begin{array}{l}\text { The term "private" simply means that the university's funding comes from tuition, investments and } \\
\text { private donors, not from taxpayers. }{ }^{[19]}\end{array}$ \\
\hline Public University & The term "public" indicates that the university’s funding comes partly from state taxpayers. ${ }^{[19]}$ \\
\hline
\end{tabular}

Table 2. List of universities selected for pilot study

\begin{tabular}{lll}
\hline University & Category & Count of Professors \\
\hline Cornell University Weill Cornell Medical College & Private & 6 \\
Indiana University & Public & 13 \\
Marshall University & Public & 5 \\
The University of Michigan & Public & 7 \\
University of Kansas & Public & 2 \\
University of Minnesota & Public & 8 \\
University of Missouri & Public & 5 \\
University of North Carolina at Charlotte & Public & 8 \\
University of Texas & Public & 5 \\
University of Washington & Public & 6 \\
Grand Total & & $\mathbf{6 5}$ \\
\hline
\end{tabular}


This pilot study looked to investigate two fundamental questions:

- What are the academic backgrounds of Healthcare Informatics faculty?

- Do the disciplines mirror the inter-disciplinary nature if the Healthcare Informatics field itself?

The academic backgrounds of the faculty in this pilot study is fairly diverse. Table 3 shows the areas in which the PhD's have been granted.

Table 3. List of doctoral degree disciplines of healthcare informatics professors

\begin{tabular}{|c|c|}
\hline PhD Discipline & Count Disciplines \\
\hline Anthropology & 1 \\
\hline Behavioral decision theory & 1 \\
\hline Biochemistry & 1 \\
\hline Biochemistry \& Molecular Biology & 1 \\
\hline Biomedical Informatics & 1 \\
\hline Biometry & 1 \\
\hline Business Administration & 1 \\
\hline Chemical Engineering & 1 \\
\hline Comparative Literature & 1 \\
\hline Computer Engineering and Computer Science & 1 \\
\hline Computer Science & 10 \\
\hline Computer Science and Engineering & 1 \\
\hline D.Phil. & 1 \\
\hline Department of Cognitive Science & 1 \\
\hline DNP & 1 \\
\hline $\begin{array}{l}\text { Doctor of Philosophy in Educational Leadership \& } \\
\text { Policy Analysis }\end{array}$ & 1 \\
\hline DrPH & 1 \\
\hline Ed.D & 1 \\
\hline Engineering and Public Policy & 1 \\
\hline Epidemiology & 1 \\
\hline Health behavior and health education & 1 \\
\hline Health Finance and Organization & 1 \\
\hline Health Informatics & 4 \\
\hline Health policy & 1 \\
\hline Health services organization and policy & 1 \\
\hline Healthcare Strategic Management & 1 \\
\hline Information and media studies & 1 \\
\hline Information Science & 2 \\
\hline Information Technology & 1 \\
\hline M.D. & 5 \\
\hline Machine learning & 1 \\
\hline Machine Learning in Healthcare: Health Informatics & 1 \\
\hline Medical Computer Engineering & 1 \\
\hline Medical Informatics & 1 \\
\hline Medical Information Sciences & 1 \\
\hline Methodology and Evaluation Research & 1 \\
\hline Not listed & 4 \\
\hline Nursing & 1 \\
\hline $\mathrm{PhD}$ & 1 \\
\hline Public health & 1 \\
\hline Public policy & 1 \\
\hline Robotics & 1 \\
\hline Sc.D & 1 \\
\hline Statistics & 1 \\
\hline Systems Sciences and Electrical Engineering & 1 \\
\hline Grand Total & 65 \\
\hline
\end{tabular}

Table 4 shows the areas in which the Graduate/Master's Degree's have been granted.

Table 4. List of garduate degree disciplines of healthcare informatics professors

\begin{tabular}{ll}
\hline Graduate Discipline & Count Disciplines \\
\hline Anthropology & 1 \\
Behavioral decision making and economics & 1 \\
Biomedical Engineering & 1 \\
Biophysics & 1 \\
Chemical Engineering & 1 \\
Comparative Literature & 1 \\
Computer Engineering & 1 \\
Computer Science & 8 \\
Computer Science and Engineering & 1 \\
Department of Cognitive Science & 1 \\
Electrical and Computer Engineering & 1 \\
Electrical Engineering & 2 \\
Epidemiology & 1 \\
Fisheries Genetics & 1 \\
General Experimental Psychology & 1 \\
Health Administration & 1 \\
Health Administration Executive Masters & 1 \\
Healthcare Management & 1 \\
Information Systems & 1 \\
library sciences & 1 \\
M.P.H. & 1 \\
M.S. & 1 \\
Marketing and Management Information Systems & 1 \\
Master of Health Administration & 1 \\
Mathematics & 1 \\
MBA & 1 \\
Medical Informatics & 1 \\
Mgt./Supr. Health Care Adm & 1 \\
MLS & 1 \\
MS & 1 \\
MSN & 1 \\
Not listed & 1 \\
Preventive Medicine & 1 \\
Public Health & 1 \\
Public Policy Analysis & 1 \\
Robotics & 1 \\
School of Medical Sciences & 1 \\
Social work & 1 \\
Grand Total & 1 \\
\hline
\end{tabular}

Table 5 shows the areas where the Undergraduate Degree's have been granted.

In this pilot study, one trend was apparent in the academic backgrounds of the HIT faculty. Computer Science was the most common academic background of the faculty (10 PhD's, 8 Graduate and 6 Undergraduate Degrees). Interestingly, four faculty members earned a $\mathrm{PhD}$ in Health Informatics and no faculty member had earned a graduate/undergraduate degree in HIT. 
Table 5. List of undergraduate degree disciplines of healthcare informatics professors

\begin{tabular}{ll}
\hline Undergraduate Discipline & Count Disciplines \\
\hline Applied Mathematics & 1 \\
Applied Mathematics \& Computer Science & 1 \\
B.A. & 2 \\
B.A.Sc & 1 \\
BA & 1 \\
Bachelor of Arts in Psychology & 1 \\
Biochemistry and Molecular Biology & 1 \\
Biology & 1 \\
Biology and Computer Science & 1 \\
BSN & 2 \\
Chemical Engineering & 1 \\
Chemistry & 1 \\
Computer Science & 6 \\
Department of Biological Sciences & 1 \\
Divisional Science & 1 \\
Economics & 1 \\
Economics & 1 \\
Electrical Engineering & 1 \\
English & 1 \\
Fisheries Biology & 2 \\
Health and Society & 1 \\
History & 1 \\
Marketing & 1 \\
Mathematics & 1 \\
MBBS, (US Equivalent of Doctor of Medicine) & 1 \\
Med. Tech/Education & 1 \\
Not listed & 17 \\
Anthropology/Psychology & 1 \\
Nuclear Engineering & 1 \\
Pharmacy & 1 \\
Philosophy & 1 \\
Physics and religious studies & 1 \\
Psychology & 1 \\
Science & 1 \\
Science and math & 1 \\
Women's studies & 1 \\
Zoology & 1 \\
Grand Total & 1 \\
\hline & 1 \\
\hline
\end{tabular}

Do the disciplines mirror the inter-disciplinary nature if the Healthcare Informatics field itself? The faculty members of the ten universities investigated in this pilot study indicated 45 unique $\mathrm{PhD}$ disciplines. By any measure, that would be considered inter-disciplinary. Thirty-nine graduate disciplines and thirty-seven undergraduate areas were found to be academic backgrounds of the Healthcare informatics faculty.

\section{Discussion}

This pilot study has demonstrated that the academic backgrounds of 10 sample universities and the 65 professors selected demonstrate the inter-disciplinary nature of Healthcare Informatics. Virgona (2014) ${ }^{[1]}$ found the course distribution of Healthcare Informatics to follow this inter-disciplinary path (see Table 6).

Table 6. Course distribution of healthcare informatics courses

\begin{tabular}{ll}
\hline Disciple & \% of Healthcare Informatics course \\
\hline Business & $10 \%$ \\
Health Care & $9.1 \%$ \\
Healthcare Informatics & $27 \%$ \\
Information Systems & $53 \%$ \\
\hline
\end{tabular}

While 53\% if the courses in Healthcare Informatics are in the Information Systems discipline, less than $2 \%$ of the $\mathrm{PhD}$ in this pilot study earned a $\mathrm{PhD}$ in Information Systems. In a similar discovery, $10 \%$ of Healthcare Informatics curriculum is business related yet there is no evidence of any business background of the Healthcare Informatics faculty.

Despite this disparity, it is not clear or known if this is an issue that needs to be addressed. Future research should investigate if the lack of academic qualifications presents curriculum problems in a relatively new field. Is there a clear definition for Healthcare Informatics faculty or is each institution addressing the multi-disciplinary needs on a caseby-case basis?

\section{CONFlicts OF InTEREST Disclosure}

The author declares that there is no conflict of interest.

\section{REFERENCES}

[1] Virgona T. Towards an Empirical Definition of Graduate School Healthcare Informatics. Canadian Journal of Nursing Informatics. 2014; 9(12): 3555.

[2] Hook SA. Teaching health informatics: designing a course for a new graduate informatics program. Journal of the Medical Library Association. 2003; 490-2. PMid:14566381

[3] Greenes RA, Shortliffe EH. Medical InformaticsAn Emerging Academic Discipline and Institutional Priority. JAMA. 1990; 1114-1120.
PMid:2405204 http://dx.doi.org/10.1001/jama.1990.034 40080092030

[4] Bakken S. An Informatics Infrastructure Is Essential for Evidence-based Practice. J Am Med Inform Assoc. 2001; 199201. PMid:11320064 http://dx.doi.org/10.1136/jamia. 200 1.0080199

[5] Hersh W. Who are the Informaticians? What we know and should know. J Am Med Inform Assoc. 2006; 13(2): 166-170. PMid:16357354 http://dx.doi.org/10.1197/jamia.M1912 
[6] Bell MJ. The IT staffing crisis. Health Management Technology. 1998; 65-66.

[7] McNeil BJ, Elfrink VL, Bickford CJ, et al. Nursing information technology knowledge, skills, and preparation of student nurses, nursing faculty, and clinicians: A U.S. survey. Journal of Nursing Education. 2003; 341-9. PMid:12938896

[8] Hersh W. Medical informatics education; an alternative pathway for training informationists. J Med Libr Assoc. 2002; 90(1): 76-79. PMid:11838463

[9] Shortliffe E. An Overview of Biomedical Informatics. 2006. Available from: http://www.apami.org/apami2006/ppt/1027-S hortliffe.pdf

[10] Dalrymple PW. Data, Information, Knowledge: The Emerging Field of Health Informatics. Bulletin of the American Society for INformatin Science and Technology. 2011; 41-44.

[11] Rusnakova V, Bacharova L, Boulton G, et al. Assessment of Management Education and Training for Healthcare Providers in the Slovak Republic. Hospital Topics. 2004; 18-25. PMid:15754858 http://dx .doi.org/10.3200/HTPS.82 .3.18-25

[12] Fowler F. Survey research methods. Thousands Oaks, CA: Sage Publisher. 2002.
[13] Berg B. Qualitative research methods for the social sciences (4th ed.). Boston: Allyn and Bacon. 2001.

[14] Kampov-Polevoi J, Hemminger BM. Survey of Biomedical and Health Care Informtics programs in the United States. Journal of the Medical Library Association. 2010; 98(2). PMid:20428287 http://dx.doi.org/10.3163/1536-5050.98.2.014

[15] Glebocki J. In search of the wild hypothesis: an adventure in statistics for non-statisticians . Parker, CO: Anderson-Bell. 1984.

[16] Senate Committe on Health, Education, Labor and Pensions. Executive Summary. 2014. Available from: http://www.help.senate.gov/imo/media/for_profit _report/ExecutiveSummary.pdf

[17] Anonymous. College Size: Small, Medium or Large? 2014. Available from: http://www.collegedata.com/cs/content/con tent_choosearticle_tmpl.jhtml?articleId=10006

[18] State of New Mexico. State of New Mexico Higher Education. 2014. Available from: http://www.nmcpr.state.nm.us/nmac/parts /title05/05.007.0014.htm

[19] Grove A. Private University. Available from: http: //collegeapps.about.com/od/glossaryofkeyterms/ $\mathrm{g} / \mathrm{private-university-definition.htm}$ 